Article

\title{
Promoting Interculture in Participation in German Urban Planning: Fields of Action for Institutional Change
}

\author{
Sandra Huning ${ }^{1, *}$, Christiane Droste ${ }^{2}$ and Katrin Gliemann ${ }^{1}$ \\ ${ }^{1}$ Faculty of Spatial Planning, TU Dortmund University, 44221 Dortmund, Germany; \\ E-Mails: sandra.huning@tu-dortmund.de (S.H.), katrin.gliemann@tu-dortmund.de (K.G.) \\ 2 UP19 Stadtforschung + Beratung GmbH, 10317 Berlin, Germany; E-Mail: droste@up19.eu \\ * Corresponding author
}

Submitted: 15 November 2020 | Accepted: 22 February 2021 | Published: 27 April 2021

\begin{abstract}
Germany has been a host country for immigrants for a long time, but an institutional transformation to promote interculture in urban public administration in general, and participation in urban planning in particular, has only just begun. This article addresses institutional frameworks and proposes strategic elements for interculture in participation, based on transdisciplinary, participatory, and transformative research in two German cities. Interculture means overcoming access barriers, based on cultural norms and stereotypes, to open up participation for groups who have been underrepresented so far. The article presents four types of barriers to interculture: a selective implementation of interculture guidelines, an institutional culture that leaves room for 'othering' of immigrant groups, top-down definitions of participation procedures, and an inter-departmental division of labour. In response to these barriers, we elaborate two fields of action: the establishment of spaces for reflexivity and of a 'phase zero' that helps to build trust and long-term relationships with immigrant communities. These fields of action do not offer any concrete road map. Instead, they focus on the institutional context for action, its structures, self-understandings, and the scope for individual action, and are thus much harder to address. The transformative, participatory, and transdisciplinary research setting bears both challenges and potential, but the article argues that it is beneficial for urban studies in light of the challenges that cities are facing.
\end{abstract}

\section{Keywords}

Germany; institutional transformation; interculture; migration; participation; public administration; real-world laboratory; transdisciplinary research

\section{Issue}

This article is part of the issue "Migration-Led Institutional Change in Urban Development and Planning" edited by Robert Barbarino (TU Dortmund University, Germany), Charlotte Räuchle (Free University Berlin, Germany) and Wolfgang Scholz (TU Dortmund University, Germany).

(C) 2021 by the authors; licensee Cogitatio (Lisbon, Portugal). This article is licensed under a Creative Commons Attribution 4.0 International License (CC BY).

\section{Introduction}

Since the 1960s, Germany has been a host country for immigrants and refugees. According to the 2019 German sample census, about $26 \%$ of the German population have a so-called 'migration background' (Migrationshintergrund), which is the statistical category attributed to first-generation immigrants and their descendants (Destatis, 2020). Proactive integration poli- cies and measures, however, have only fairly recently been discussed and implemented. According to earlier conceptions of integration, immigrants and their families were expected to somehow automatically assimilate and 'blend into' a German mainstream society that was imagined as homogeneous and self-contained. Unsurprisingly, this did not happen as smoothly as expected. Although some 'blending in' did take place over time, changing German society in many ways, statistically the category 
'migration background' still has an impact on different social spheres such as educational performance, employment, or political representation.

Another area where, according to many planners, a 'migration background' plays out is participation. In Germany, citizen participation (Bürgerbeteiligung) is a legal obligation for spatial interventions according to the code of building law. It intends to offer stakeholders the opportunity to voice their concerns and-directly or indirectly-influence decision-making processes. In some cities, it is the task of municipal planning departments to organise participation; in others, they assign this task to intermediaries or private planning agencies. Participation processes and methods vary-somewhat along the 'ladder of citizen participation' (Arnstein, 1969)-from information events to participatory workshops and self-governed neighbourhood funds.

An important objective of these efforts is to address and mobilise organised civil society, home and shop owners, small entrepreneurs, and residents across all classes and milieus. However, it turns out that in many participatory events that are 'open to all' only the so-called 'usual suspects' (Groeger, 2002) show up, who are more often male than female and tend to have an academic and native German background. There have only been a few efforts to transfer successful strategies for approaching underrepresented groups from urban renewal programmes to 'mainstream' planning events and procedures (Difu, 2003).

Interculture is still not part of most job descriptions in planning departments, and it is not always easy for planners to translate the needs of interculture into their own task areas. However, while a lack of strategic knowledge and resources could be addressed more or less easily, we argue in this article that barriers exist beyond the immediate participation process, related to the institutional framework, which prevent a more comprehensive integration of issues of 'interculture' into participatory planning.

In this article, we present findings from on-going research that strives to find ways for making participation processes more inclusive in a participatory, transformative, and transdisciplinary research setting. Similar to much of the existing literature, the research searches for strategies for the enhancement and better understanding of participation and the broader inclusion of different (immigrant and non-immigrant) groups in urban development (Eurocities, 2014). In this article, the presented arguments highlight the second focus of our research, which aims at identifying and transforming institutional frameworks to promote interculture in participation (Scholten, 2020). The research complements literature on intercultural opening and institutional change by applying these concepts in the context of participation in urban development and by drawing attention to institutional barriers and fields of action that impact or prevent institutional change.
In Section 2 of the article, we introduce the concepts of 'interculture' and 'intercultural opening,' which address the need for a systematic institutional change to reduce barriers related to a 'migration background' in different institutional settings and societal areas. By addressing mechanisms of exclusion and 'othering' (Ahmed, 2012; Jungk, 2001), the interculture concept draws attention to power imbalances and the effects of privilege (Gaitanides, 2016, p. 119; Roska, 2012 , p. 7). At the same time, it presents dimensions of institutional change for interculture in participation (Terkessidis, 2018). In Section 3, we present our research design and methods. In Sections 4 and 5, we identify institutional barriers to interculture in participation and subsequently focus on two fields of action that, according to our findings, deserve more attention when it comes to an intercultural re-definition of participatory planning and, in consequence, to institutional change: the establishment (1) of spaces for reflexivity and (2) of a 'phase zero' that predates concrete participation events. Our concern is to highlight the vital role of the institutional framework for the implementation of interculture. We conclude by reflecting on the potential of transdisciplinary research settings for this type of research problems, the benefits and the risks.

\section{Interculture, Intercultural Opening, and Institutional Change}

In contrast to other European countries, Germany is still on its way from being an immigration country (Einwanderungsland) to being an immigration society (Einwanderungsgesellschaft). Thus, the institutional transformation towards interculture and diversity is an on-going process that started only recently (Terkessidis, 2018, p. 96). It is reflected in academic debates on the 'postmigration society' (Postmigrantische Gesellschaft), which plead to recognise immigration and population diversity as 'normality' that structures society, and to establish a narrative on a "new, pluralistic national identity, open to immigration that becomes in a mid-term perspective part of the collective memory" (Foroutan, 2019, p. 219). This would need a "new dynamic of integration, based on recognition, negotiation, ambivalence, antagonism and alliance" (Foroutan, 2019, p. 24) with an impact on the (co-)production of urban space. Protagonists also argue that the 'othering' of both immigrants and their descendants, for whom they have invented the terminology 'new Germans' (Neue Deutsche), naturalises social inequalities and unequal societal participation and suppresses plurality, even if it results from the explicit wish to act in favour of othered 'target groups' (Terkessidis, 2017, p. 36). They have also shown how, intentionally or not, 'othering' is potentially linked to racism (Ahmed, 2012).

Organisational approaches and related academic debates on intercultural opening since the early $2000 \mathrm{~s}$ focus on top-down systematic approaches, human 
resource development (in terms of interculture competencies in public administrations) and the cooperation of public authorities with migrant self-help organisations (Migrantenselbstorganisationen, MSOs; Gaitanides, 2016, p. 122; Schröer, 2018). Many municipalities have established (non-binding) training programmes to build up intercultural competence among their staff and adopted 'diversity management strategies' in order to counter the risk of culturalisation of public action (Schröer, 2018, pp. 243-256). While protagonists of the postmigration discourse demand a pro-active critique of racism, based on postcolonial theory, recent literature on strategies for intercultural openings of public administrations (Colinas, 2018; Gesemann \& Roth, 2018) fails to explicitly acknowledge institutional racism and the-often gendered-power structures related to them (Scholten, 2020, p. 220). A reflection of white privilege (Dyer, 1997) is still missing both in intercultural opening literature for public administrations and in public (planning) administration.

In terms of participatory urban planning, target group-focused strategies have been playing a significant role, although they are ambivalent. On the one hand, targeting and homogenising city users 'with a migrant background' in participatory planning has been interpreted as yet another example for racialising practices by public institutions and for "differentiating power" (Terkessidis, 2004, p. 99). On the other hand, authors have argued that the explicit recognition and representation of oppressed groups supports their self-organisation and empowerment (Young, 2005).

An example that illustrates this ambivalence is the German Socially Integrative City (Soziale Stadt; or, since 2020, Sozialer Zusammenhalt) programme, initiated in 1999, which targets deprived neighbourhoods for extra urban renewal funding. One indicator (among others) for a deprived neighbourhood was an above-average share of residents 'with a migration background,' whose participation in urban development is an important objective. The failure of many participation concepts to reach their 'target groups' was attributed to the intermediaries carrying out the programme rather than to how public administration had planned, implemented, and steered it (Difu, 2003). At a later point, a critical governance analysis of the programme brought to light the institutional barriers to immigrant participation (Schnur \& Drilling, 2009).

A break-through for more awareness of 'superdiversity' as "transformative diversification of diversity" (Vertovec, 2007, p. 1025) or 'hyperdiversity' (Tasan-Kok, van Kempen, Raco, \& Bolt, 2013) of people 'with migrant background' was related to a survey on immigrant consumption patterns and milieus in Germany (vhw, 2009). The study revealed that more or less the same milieus can be found in immigrant and non-immigrant residential groups. A recent update stated that experiences of exclusion (or self-exclusion) contribute to participatory abstinence of immigrant populations (vhw, 2018). This shows that there is still a long way to go for insti- tutions to become more sensitive towards interculture and diversity and ready to remove all structural hurdles, "mostly invisible, unspoken and unnoticed obstacles" (Terkessidis, 2018, p. 9).

In terms of implementing interculture, the following strategic elements come up repeatedly (Gaitanides, 2016): (1) the discursive development of an intercultural mission statement; (2) quantitative monitoring of involved or affected groups; (3) a qualitative analysis of access barriers; (4) the dismantling of these barriers; (5) external networking with integration officers and MSOs; and (6) human resources development. Intercultural opening, defined as a cross-sectional management task, requires "bottom-up linkage to the workforce" (Gaitanides, 2016, p. 123). Strategically, this means a step-by-step internal re-organisation of institutions and of their collaboration with others, which works not only for public institutions but also for MSOs and civic initiatives. Also, Terkessidis (2018, pp. 142-161) pleads for more strategic interventions in terms of (1) the institutional culture in the sense of its constitution, rules, and norms (which, for example, can be laid down in a jointly developed interculture code); (2) the workforce (evidence-based, proactively targeted recruitment campaigns); (3) the material design of spaces and communication proposals; and (4) the basic strategic orientation. He demands "verifiable standards, comprehensible goals and also the necessary flexibility to be able to change direction if something does not work" (Terkessidis, 2018, p. 165).

There has been little research so far on the implementation of interculture in planning and its effects and, more generally, on the transferability of the concept to this field. Manuals address interculture in participation mainly with reference to material design and communication tools (Landeshauptstadt Wiesbaden, 2015; SenStadtUm, 2011; SenSW, 2019; Stiftung Mitarbeit \& ÖGUT, 2018). A recent evaluation of democratic reliability, representativeness, and transparency of participation processes in Germany showed that as a political goal, diversity is reflected in objectives, methods, and tools for participation, but not in terms of institutional change (Selle, 2019, p. 37). The author found that one of the key requirements for a jointly developed interculture code for planning processes-transparency of internal processes - was often not fulfilled and remained an issue of power (Selle, 2019, p. 41). In contrast to the present practice, he called for evaluations of participants and the interests they represent (Selle, 2019, p. 35). Another important issue that has been documented in guidelines and political goals, but hardly ever translated into recruitment practices, is the diversification of the planning staff. Based on these observations, the research presented here took an institutional approach to rethink barriers to interculture in participation and to enhance encounters between planning authorities and post-migration civil society. 


\section{Research Design, Methods, and Database}

To translate interculture into the field of participatory urban planning, we developed a transformative, participatory, and transdisciplinary research setting in the context of a three-year project, funded by the German Federal Ministry of Education and Research, which will end in May 2021. The project aims to understand how to design participation processes in urban development so that they become more accessible to residents, local shop owners, and small entrepreneurs with migrant and non-migrant backgrounds. One focus is on the role of online services.

In two urban neighbourhoods, located in two big German cities, the project initiated real-world laboratories (RWLs; Renn, 2018; Wanner et al., 2018), displayed as the two case studies in Figure 1. RWLs are important research frameworks for transformative research (Scholl \& Kemp, 2016) because they aim at co-designing and testing solutions for urban problems, thus changing institutional or individual routines and behaviour.
Transdisciplinary research teams define and co-produce both problems and solutions in collective research processes. In the case of this research, the core team consists of co-researchers from academia (urban planning and design faculties), professional consultancies, and state and municipal employees in urban administrations. Also, two so-called 'inner-administrative RWL project groups' (verwaltungsinterne Projektgruppen, ViPs) with members from different departments concerned with participatory urban development and planning, migration and integration, and human resources development, were established to accompany the research process. The core team organised real-world interventions and experiments to further elaborate strategies for an intercultural opening (see Figure 1). Some authors have called transdisciplinary research "inherently inefficient" due to, e.g., different performance criteria and levels of commitment, but we agree with their expectation that it will "produce high social and academic impact when undertaken properly" (Gaziulusoy, Ryan, McGrail, Chandler, \& Twomey, 2016, pp. 57, 63).

\section{RWL-Process}

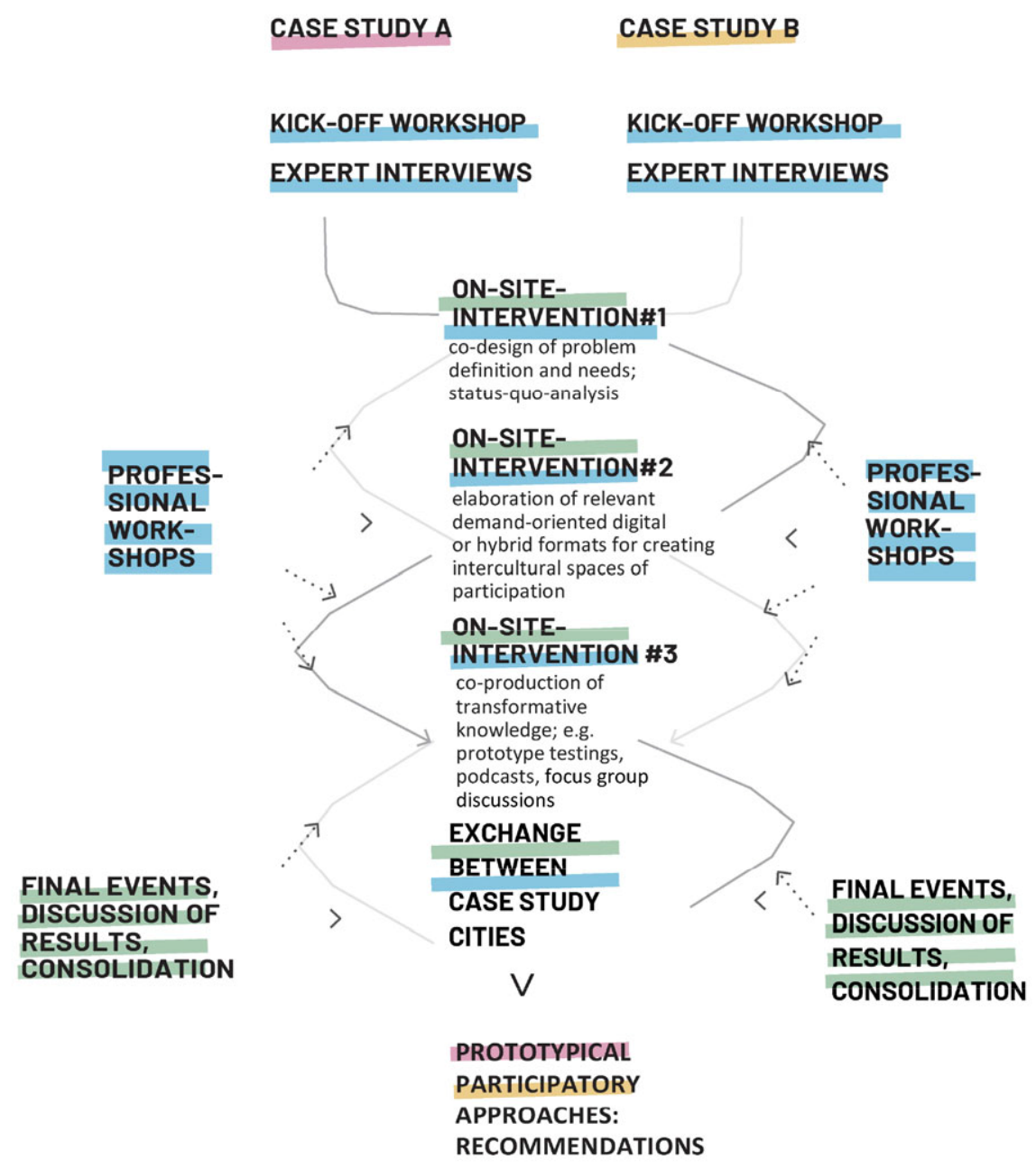

Figure 1. RWL process. Source: INTERPART Project. 
For the mobilisation of stakeholders as coresearchers and research participants, the organised interventions and workshops needed to provide exactly the kind of intercultural participatory settings that the research intended to identify. To meet this challenge, the team kept adapting and differentiating the participatory co-design methods continuously, based on both the gained experiences with different engagement strategies and on topical findings from interventions and workshops. The methodical approach differed according to the type of co-researchers: Participatory co-design methods that addressed residents and initiatives were primarily based on boundary objects and storytelling formats. In contrast, the co-research with municipal employees and intermediate actors relied on guided interviews and interactive workshop formats such as world cafés, small group and online discussions.

The findings presented in this article are based on 24 expert interviews, ten professional workshops with administrative staff, and an analysis of relevant local documents and guidelines on citizen participation and interculture/integration. All interviewees-selected either because of their professional roles or their individual interest and engagement for interculture and participation-work at various levels of administration and deal with the topic of participation in a broader sense, mostly in planning departments, but also in the field of statistics, civic engagement, anti-discrimination, etc. Many of them were members of the abovementioned ViPs. Half of the interviewees were women and the other half men, and eleven out of 24 interviewees held leadership positions. The research team recorded and transcribed the interviews and analysed them, following the research style of grounded theory (Strauss \& Corbin, 1997), using theoretical coding (Flick, 2005 , pp. 258-271) in a process that included alternating phases of open and axial coding with the software MAXQDA (Kuckartz \& Rädiker, 2019). The professional workshops included the presentation of interim results, the common interpretation of findings, and conclusions for the respective next steps. Based on the minutes, the research team extracted the core statements and used the core coding categories of the interview analysis for interpretation. One key objective was the specification of the interculture concept for participation in urban development.

The transdisciplinary research setting helped the researchers from different institutional backgrounds recognise and reflect on their 'situated knowledge' (Haraway, 1988) and to better understand the relational dimension of knowledge and knowledge production. Discussing and validating the findings with the ViPs proved to be an excellent case in point. It brought to the fore different positionalities and embodied knowledge across co-researchers of different genders, 'migration backgrounds,' and professional roles, assumptions of sameness and difference, and personal attitudes. At the same time, it helped to develop a basic common under- standing of the research. Framing research encounters as performative interventions, where identities are not only presented but also reconstructed (Rose, 1997; Valentine, 2002), called for reflexivity during the entire process.

\section{Institutional Barriers to Interculture in Participation}

To identify institutional barriers to interculture in participation, the expert interviews with municipal staff proved to be an informative source, as the discussions covered topics such as intercultural opening, racism in institutions, or (online) participation in urban development. The analysis of the research data shows that institutional barriers to participation often relate to well-thought-out bureaucratic structures and procedures that match the needs of the administration but are hard to understand and not always very appealing to people outside the institutions. In transdisciplinary research, the need to explain these apparently self-evident common-sense realities and norms tends to cause long debates and sometimes frustration, but it may be exactly these factors that make a difference. We clustered the institutional barriers we found into four types:

First, selective implementation of interculture concepts: For many employees in public administrations, interculture seems to have little to do with their job description. Accordingly, they perceive interculture concepts-even if fixed in guidelines of the municipality-as an option, not a self-evident task. A municipal staff member described it as follows:

If I were to ask my colleagues: "Intercultural opening, what does that mean to you and what do you think about it?" I would certainly be met with astonished looks, not because they don't care about the topic or because they reject it, but simply because they don't have it on their radar in their everyday lives, because it hasn't played a big role so far. (\#cd013, translations here and in the remainder of the article by the authors)

As a result, the topic is anchored unequally in different municipal departments and its implementation depends to some important extent on individual attitudes. An interculture code as proposed by Terkessidis (see before) is a crucial step towards a transformation of 'institutional culture,' but it needs to be specified and anchored in evaluable implementation measures.

Second, processes of 'othering': Another barrier we identified in our data is the 'othering'-often without thinking-of clients and colleagues who are attributed a migration background, regardless of their origin, selfdefinition, and preferences. Protest by the 'othered' individuals is often interpreted as personal sensitivity (\#ws01w). In interviews with municipal staff members, some described certain ethno-cultural groups as homogeneous, backward, and traditional. Examples include the generalising assumption of a hierarchical under- 
standing of gender roles (\#hs024) or the expectation that migrants have little understanding of participatory approaches because they expect state institutions to act in an authoritarian manner (\#pp001, \#cd005).

These attributions that homogenise, simplify, and normatively classify a highly diverse 'group' are part of current institutional cultures and as such to some extent accepted. 'Othering' may also refer to terminology, like the before-mentioned residents ' with a migration background.' Addressed in these terms, they may not feel invited to participate. Although the term 'citizen participation' seems innocent enough, apparently it does not appeal to those residents without German citizenship (around 14\% of the population in 2019; Destatis, 2020). Processes of 'othering' are difficult to discuss, particularly when linked to institutional racism. One reason might be the widespread perception of racism as an intentional individual attitude. At the same time, this indicates a lack of space to reflect on one's daily routines, which are also shaped by structural conditions.

Third, top-down definition of accessibility: Local administrations often design institutional services and tools without consulting the persons in need of their services as experts or-in an advocate position-their selforganisations. Planners state that they observe unequal access to participation, but do not always reflect that the reasons may be linked to how they design the participation process. Instead, they stress the public character of participation, which provides - from their point of view equal opportunities for everyone to participate. When asked if they had planned any participation events specifically for an intercultural encounter, a municipal staff member answered: "Not that I know of....This does not mean that the events are only for Germans but that there are events that take place and whoever comes is there" (\#hs025). A lack of multilingual information or invitations in an easy-to-understand language are typical examples of this type of barrier, based on implicit notions of normality, in this case regarding language skills and educational level. This kind of constraints can be classified as what Terkessidis calls material design in institutions, such as accessibility of buildings, forms of communication and media design, or the scheduling of participation events (Terkessidis, 2018, pp. 151-155).

Fourth, horizontal and vertical division of labour: The data suggest that planning departments often lack direct contact with the urban population and notably migrant communities. One reason for this 'contact gap' can be found in administrations' organisational and communication structures. In the sense of a division of labour between public administration and service providers or intermediaries, the municipal administration is responsible for strategic decisions on participation, while service providers like planning companies or neighbourhood management offices implement participation concepts and do the work 'on the ground.' One interviewee who works in urban planning stated that intercultural dialogue was an important objective in urban renewal for deprived neighbourhoods, but not in her professional field that addressed the public in more general terms (\#sh001). A similar division of labour exists on a horizontal level between different departments, which can lead to a silo mentality and a lack of harmonisation.

Although programmes, projects, and manuals are in place that aim at overcoming the migrant/nonmigrant dichotomy and promote interculture, it obviously remains a difficult task in the context of longestablished institutional routines. Often, these efforts are bundled in pilot-projects or programmes with a strong social objective, such as local integration strategies for refugees. When interculture is to be introduced across the board, far-reaching efforts are needed to remove institutional barriers, which do not rely only on the personal commitment of individuals. The following sections specify examples of such efforts.

\section{Promoting Interculture in Participatory Planning: Two Fields of Action}

In this article, the focus is on institutional change towards interculture in participatory planning. The findings presented in Section 4 suggest that in the two case study cities, many planners recognise the need to enhance interculture and have strategic and methodical knowledge, even if they do not feel responsible for the implementation themselves. However, for the systematic implementation of interculture targets in (participation for) urban development, the institutional framework is also important. Coupled with a strong political commitment, the institutional framework cannot only support planners to promote interculture but also provide them with networks and cross-sectoral knowledge. Based on the analysis of barriers, the research team identified four fields of action: (1) the establishment of spaces for reflexivity within (planning and related) departments; (2) a 'phase zero' that starts before participation processes for any specific planning project; (3) staff recruitment and human resources development; and (4) the creation of inter-departmental linkages, so that 'silo thinking', which sometimes prevents linkages between departments working on different angles of the same problems, can be overcome. In this article, we focus on the first two fields of action.

\subsection{Spaces for Reflexivity}

The RWLs provided evidence that spaces for reflexivity of institutional and professional cultures are essential for institutional change in general, and for intercultural opening in particular. These spaces can be defined as temporally and spatially fixed opportunities for exchange. They may be either explicitly dedicated to interculture-related topics or casual networking events for different actors that leave room for open debate. The research team pursued different strategies to create these spaces. In one case study city, members of 
the research team joined a regular cross-departmental 'jour fixe' on participation to initiate a debate on the relevance of interculture in different fields of planning. For the first time, participants from different departments shared their professional experiences on this topic and discussed ways of 'mainstreaming' good practice.

The research team also organised two digital conferences on online participation and institutional racism, which brought together municipal officers, immigrant initiatives and NGOs and gave room for different perspectives, needs and strategic impulses for developing targeted online resources and social media. In the other case study city, the research team invited municipal participation and integration officers and planners to develop a joint strategy to combine participation and integration guidelines. Also, the team organised a two-day online meeting for the ViPs from both case study cities and provided the opportunity for them to present, discuss, and contextualise their respective strategies and experiences. The feedback from these events showed that participants welcome these opportunities to support intercultural opening and a change of institutional culture. The events provided a 'protected space' for collective professional and individual reflection on topics that had rarely been addressed before. An external facilitator (like a research project) proved to be useful both in department-specific and cross-departmental cooperation that is relevant for spatial intervention.

While reflection is worthwhile in any field of professional practice, the spaces we propose need to offer the opportunity for reflexivity (Rose, 1997), where 'taboo' topics like discrimination, privilege, and racism can also be addressed. One important issue is the personal understanding of interculture and its benefits. Interviewees and workshop participants from both local administration and NGOs understood interculture either in the sense of a better representation of particular target groups or in the sense of a representative turnout of participants. An integration officer stated in an interview:

So that means I can always say I have the age groups; I have the genders; I have whatever and of course also groups of a certain origin. And when.... have a certain percentage of people with a European migration background, then [the process] should be representative-unless it is a target-group oriented project where....I'm only addressing the target group. (\#pp001)

Some co-research partners drew attention to the fact that a 'migrant background' in itself is of no greater importance for participation than other social categories such as class or gender, and that intersections between these categories must be considered. As one interview partner put it: "One cannot say that the group of migrants is homogeneous and there can be one single solution for addressing them. It is diverse, right?" (\#sh002). However, as in public debate in general, the homogenising of cultural stereotypes does exist in participatory planning as well. During the research, there was a constant tension between, on the one hand, the reference to 'particular needs' of immigrant groups, thus essentialising cultural difference, and, on the other hand, the assumption that in a super-diverse urban society, every individual is different and different barriers of access need to be addressed equally. As the following quote illustrates, planners recognise the need to reflect institutional and individual prejudice, bias and eventually racism, which needs time and space:

This also has to do with power: How can you get people involved who usually do not have much influence, for example? Or how can participation become legitimate, in the sense that as many people as possible are involved, to get a broader picture of people's interests? (\#sh002, interviewee from an urban development department)

Other issues that are hard to tackle in traditional onthe-job training are individual positionalities and experiences with privilege and discrimination. Despite some people's (self-)understanding, planners are not neutral experts, but people with a particular social position, too, which they do not often have the opportunity to ponder. As one interviewee from the urban renewal department argued, the staff's attitude toward interculture depends necessarily to some degree on personal experience with discrimination and privilege. While negative experiences are part of some people's lives, it is a mere 'luxury' for others to think about interculture, apparently because they are not confronted with stereotypes and discrimination in their everyday lives. Accordingly, they need incentives to reflect upon interculture (\#sh001). The RWL debates illustrated the difficulties to address these questions among colleagues. Some interviewees linked interculture and diversity competencies to selfevident aspects of living together such as democracy, respect, and empathy (\#cd008, \#cd009) and to questions of planning efficiency (\#sh002). However, what is self-evident to some is not at all self-evident to others. A change of perspective needs spaces for reflexivity.

A third important issue that came up in several interviews and workshops and also deserves more attention is language-not only in terms of multilingual settings for participation and publicity material, but also the translation between planners' bureaucratic terminology and everyday concerns. One interviewee from a neighbourhood development team, with particular focus on the integration of newly arrived refugees, stated: "By language, I do not just mean different languages, but...professional language so that many people say, 'I can hear, but I cannot understand"' (\#cd006). This last issue not only concerns immigrants but many residents, local shop owners, and small entrepreneurs-migration background or not-who have trouble understanding bureaucratic language and procedures. Planners need to 
reflect on how this privileges particularly well-organised (academically trained) interest groups who can influence decision-making processes to their advantage.

\subsection{Phase Zero}

The RWLs show that it takes a 'phase zero' for constant networking and dialogue so that MSOs and other initiatives are not only addressed when it comes to concrete participation projects but that a common trust base is established. For the interviewees, 'good' participation means procedures that directly address stakeholders at the local level, in spaces and settings they use regularly and are accustomed to. Interviewed members of MSOs particularly welcome the idea of being proactively invited and included in urban decision-making processes, as they position themselves as representatives for migrants' interests in all policy areas. Municipal interviewees, particularly with a background in integration and immigration departments, also consider MSOs to be important stakeholders and bridging institutions between planners and urban residents with a migrant background (\#pp001). This corresponds to the hypothesis that inter-group contact has positive effects on the reduction of stereotypes and prejudices-under three conditions: cooperation (working together for common goals), encounter at eye level (similar status), and support of private-public interaction by authorities or institutions (Allport, 1954; Dangschat \& Alisch, 2014). However, many planning departments have no capacities to keep in touch beyond immediate consultation needs, which makes it harder to maintain an appreciative relationship. According to co-researchers from different spheres, only a personal and long-term approach can help to build trust, as personal trust relates to people, not functions. Thus, a trustful relationship could be interrupted when a particular contact person leaves the department. Particularly in times when a new generation enters municipal administrations, transitions must be planned carefully.

So far, the German planning system has no framework for a 'phase zero,' i.e., opening an intercultural dialogue long before a planning process has started. One of the case study municipalities is considering the establishment of a budget for a (part-time) position responsible for intercultural dialogue at 'eye-level' and for networking with MSOs. At the same time, the position is supposed to promote inter-administrative sensitivity and awareness for interculture. The research also contributed to the intercultural design of a local partnership for neighbourhood development. Since these activities have just started to have an effect, it is impossible to say what comes out of them. However, giving impulses for new networks and cooperation seems promising in terms of longterm institutional transformation-under the condition, however, that planners proactively counter the effects of power relations, which may result from unequal information bases, language, and rhetorical skills, but also from various definitions of belonging and identity. "Participation is something for Germans," one resident stated in a street survey undertaken by a research partner. Thus, networking can only be a first step, particularly in super-diverse urban settings. A greater diversity of participants is no end in itself but needs to be linked to policy objectives such as fighting poverty or improving education and employment opportunities. A 'phase zero' can help to keep these objectives in mind and to link participation to concrete improvements (e.g., in terms of living conditions or service provision), which may in turn motivate others to make their voice heard.

The RWLs also explored ways to create a 'phase zero' with cross-media and multilingual tools, at the same time addressing the above-mentioned question of language. Project interventions included workshops, narrative elements and installations during project events in public urban space. For example, a wooden archway with a multilingual doorbell provided a playful setting for passers-by and for local initiatives to get in touch with each other on topics such as leisure and open spaces, supported by Google Translator. The project also experimented with more comprehensive storytelling formats: one-on-one discussions, group discussions, and podcasts that presented different perspectives on local spaces and connected them. A third example was the development and testing of a user-oriented easy-language and image-oriented online-tool, which can be used for immediate feedback on concrete spaces and planning proposals. The prototype is still in the making and will be available open-access at the end of the research.

Interviewees from MSOs and intermediary organisations such as neighbourhood management see participation in urban planning and development as a medium for the empowerment particularly of refugees and those immigrants who have come to Germany only recently (\#cd006). They also stress, however, that public authorities' perceptions are often limited when it comes to the participation of immigrants: There are many other ways in which residents contribute to and participate in local development on a day-to-day basis, even if they do not join formal participation events. Often, planning departments only recognise those forms of engagement that are linked to specific planning projects and initiated by planners. However, there are many other forms of engagement such as voluntary work, assistance to neighbours, informal get-togethers, and forms of support that contribute to urban cohesion and deserve more recognition and appreciation. Taking them into consideration may also slowly result in a shift of power balance.

\section{Conclusion: Towards Interculture in Participation}

What have we learnt about strategies to promote the interculture perspective in participation? Our findings suggest that the interculture concept can be helpful to identify both barriers for participation and fields of action. It goes beyond declarations of intent or guide- 
lines and helps to support transformation in public administrations.

The interculture concept challenges planning administrations in many German cities because it calls for mainstreaming interculture into different planning sectors. Currently, the objective to counter selective participation and to expand participation of underrepresented groups is more or less well-established in urban renewal and development programmes for deprived neighbourhoods. These often include particular instruments, tools, and formats to address residents 'with a migration background' and other underrepresented social groups. A transfer of these experiences to other planning-related departments, however, only rarely takes place on a systematic basis. It takes an explicit political will and an institutional framework that allows time and space for reflexivity and for dialogue with colleagues and supervisors to implement general knowledge and institutional targets into everyone's work-even if it does not have to do with participation or immediate contact with residents 'with a migration background' on a regular basis.

All four fields of action concern institutional change at the municipal level and must be interpreted and adapted to local contexts, which vary. Although they may seem simple enough, they are by no means self-evident or uncontested, as they require strong commitment and leadership translated into frameworks for interculture and empowerment. They imply leaving individual 'comfort zones' and accepting different types of knowledge, which-as we experienced for ourselves in our research-can be a great challenge. At the same time, identifying fields of action for the promotion of intercultural participatory planning is certainly not enough, as it does not automatically propose one particular direction of change. Which action is supportive of interculture in participation again depends to some extent on the local context, e.g., in terms of the local immigration history; the social position, resources and needs of stakeholder groups whom planners meet or hope to address; and the existence and engagement of local agents of change, such as civic initiatives, migrant NGOs, and integration councils. In the super-diverse socio-spatial settings of many German cities, there can be no easy and once-and-for-all strategies.

Thus, the fields of action we identified do not offer a concrete road map, but instead, they focus on the institutional context for action, its structures, selfunderstandings, and the scope for individual action, and may thus be much harder to address, although our findings certainly suggest that they are worthwhile. The openness of the interculture and intercultural opening concepts make them 'empty signifiers' (Gunder \& Hillier, 2009) at first sight, just as sustainability or gender equity. However, these examples show that vagueness also has its benefits, as it allows labelling different activities pointing in the same direction and opens up windows of opportunity for collective action. At the same time, contradictions and ambivalences remain. For example, target-group oriented participation processes are based on definitions by planners or other administrative staff who may or may not be sensitive in terms of interculture or who may use their everyday understanding without reflecting that target group definitions themselves are expressions of power of those who define them. Furthermore, they single out certain groups 'with special needs,' homogenising and possibly victimising them. However, this can also raise awareness for those needs that get lost in other public events. The 'postmigration' perspective, on the other hand, claims that singling out target groups prevents the normalisation of immigration and the mainstreaming of interculture, as special events for particular target groups signal that it is they who need to change, not the institutional frameworks. Our impression is that although these two perspectives contradict each other, it may be these ambivalences that inspire reflexivity and lead to fruitful discussions with colleagues, civic initiatives, and other urban actors, to enhance curiosity and engagement.

This is also true for the research process itself, as the contradictions also played out here. The members of the research team represent institutions-universities, planning offices, private consultancies-and thus are caught in their particular institutional logics, restrictions, and scopes for action. They face their own institutional constraints, which certainly makes transdisciplinary research an adventure. We conclude that similar to broader political guidelines such as sustainability, gender equity, or justice, interculture is a process that needs to be constantly refined, rather than a condition that could be fixed and preserved over time. For future research, this means that researchers need to recognise, name, and reflect trade-offs between different-partly contradictory-research strategies. More than in other research settings, every strategic decision in transdisciplinary RWLs has its own benefits and pitfalls, e.g., for the relationship with research partners between respectful 'eye-level' communication, dependency, and different (political) interests. While strategic decisions are unavoidable, they certainly have an impact on research results (and how they may be instrumental to different political intentions). Complying with external expectations (e.g., of handy solutions) and at the same time insisting on the complexity of these questions and raising attention to the social construction of knowledge, to power structures and struggles for interpretative predominance prevent easy answers. There can be no perfect solutions: They must remain messy.

The way this research has addressed questions of interculture and postmigration is to some extent part of a particular German debate on collective identity, belonging, and citizenship. Consequently, it is a particular case with limited transferability to other contexts, since planning institutions in German-speaking countries differ in many ways from elsewhere, as do the understanding of participation and the way diversity, migration, and interculture are framed in politics and society. However, 
at the same time, this difference may highlight blind spots and thus help to reflect on differences and similarities and what is behind them in other contexts. It may make concepts and processes of knowledge production, as well as implicit knowledge that is usually taken for granted, accessible to debate. This research could be a first step towards an inter- or transnational exchange on these topics.

Beyond interculture, cities face many challenges today that call for a transformation of institutional frameworks. A tangible benefit of RWLs for public authorities is the experience that transformation needs to go beyond the 'usual' re-shaping of funding schemes, instruments, etc. The experience from this research shows that transdisciplinary RWLs create a better understanding of multiple perspectives, but that it takes time to establish a common working basis. Finding a balance between pragmatic solutions and standards of academic excellence challenges the boundaries between research and practice. However, transdisciplinary research will become increasingly important, and its opportunities and risks will remain on the agenda for future debate.

\section{Acknowledgments}

The findings we present in this article are based on collective transdisciplinary research funded by the German Federal Ministry of Education and Research (BMBF, support code 01UM1822AY). We are grateful to all our colleagues from the INTERPART project: Katja Adelhof, Robert Barbarino, Julia Bechtluft, Malte Bergmann, Johanna Broeckel, Keno Franke, Bianca Herlo, Gabriele Kotzke, Rogério Lopes de Pereira, Omid Nowzamani, Ivonne Peitsch, Philipp Piechura, Michelle Ruesch, Hanna Seydel, Sandra Stark, and Alexander Thom for coproducing this research, including data collection, analysis, and interpretation. We also thank our ViP members, the local initiatives, and intermediaries we worked with for their participation in interviews, workshops, and other formats of co-research, for fruitful discussions and friendly collaboration. Last, but not least, we owe thanks to four anonymous reviewers and the Academic Editors of this thematic issue for their valuable comments on this article.

\section{Conflict of Interests}

The authors declare no conflict of interests.

\section{References}

Ahmed, S. (2012). On being included. Durham, NC: Duke University Press.

Allport, G. W. (1954). The nature of prejudice. Reading, MA: Addison-Wesley.

Arnstein, S. (1969). Ladder of citizen participation. Journal of the American Planning Association, 35(4), 216-224.
Colinas, C. (2018). Die Neuen Deutschen Organisationen [The new Germans' organisations]. In T. Groß, S. Huth, B. Jagusch, A. Klein, \& S. Naumann (Eds), Engagierte Migranten: Teilhabe in der Bürgergesellschaft [Engaged migrants: Participation in the civil society] (pp. 93-99). Schwalbach am Taunus: Wochenschau Verlag.

Dangschat, J., \& Alisch, M. (2014). Soziale Mischung: Die Lösung von Integrationsherausforderungen? [Social mixing: The solution to integration challenges?]. In P. Gans (Ed.), Räumliche Auswirkungen der internationalen Migration [Spatial impacts of international migration] (Vol. 3, pp. 200-218). Hannover: ARL. Retrieved from https://econpapers.repec.org/ bookchap/zbwarlfba/141935.htm

Destatis. (2020). Bevölkerung und Erwerbstätigkeit: Bevölkerung mit Migrationshintergrund: Ergebnisse des Mikrozensus 2019 [Population and employment: Population with a migration background: Results of the microcensus 2019]. Wiesbaden: Statistisches Bundesamt.

Difu. (2003). Strategien für die Soziale Stadt: Erfahrungen und Perspektiven [Strategies for the socially integrative city: Experiences and perspectives]. Berlin: Difu.

Dyer, R. (1997). White: Essays on race and culture. London: Routledge.

Eurocities. (Eds.). (2014). Integrating cities toolkit: Engagement of migrant communities in local policy making processes and political participation. Brussels: Eurocities. Retrieved from http://nws.eurocities. eu/MediaShell/media/Engagementofmigrant communities.pdf

Flick, U. (2005). Qualitative Sozialforschung: Eine Einführung [Qualitative social research: An introduction]. Reinbek bei Hamburg: rowohlts enzyklopädie.

Foroutan, N. (2019). Die postmigrantische Gesellschaft: Ein Versprechen der pluralen Demokratie [The postmigrant society: A promise of plural democracy]. Bielefeld: transcript.

Gaitanides, S. (2016). Interkulturelle Öffnungsprozesse [Intercultural opening processes]. In T. Groß, S. Huth, B. Jagusch, A. Klein, \& S. Naumann (Eds.), Engagierte Migranten: Teilhabe in der Bürgergesellschaft [Engaged migrants: Participation in civil society] (pp. 118-124). Schwalbach am Taunus: Wochenschau Verlag.

Gaziulusoy, A. I., Ryan, C., McGrail, S., Chandler, P., \& Twomey, P. (2016). Identifying and addressing challenges faced by transdisciplinary research teams in climate change research. Journal of Cleaner Production, 123, 55-64. https://doi.org/10.1016/j.jclepro. 2015.08.049

Gesemann, F., \& Roth, R. (Eds.). (2018). Handbuch lokale Integrationspolitik in der Einwanderungsgesellschaft [Handbook local integration policy in the immigration society]. Wiesbaden: Springer VS.

Groeger, F. (2002). Quartiersöffentlichkeit, Bewohnerbeteiligung und lokale Politik im "Problemviertel": 
Eine Fallstudie [Neighborhood public, resident participation and local politics in the "problem neighborhood": A case study]. In U.-J. Walther (Ed.), Soziale Stadt: Zwischenbilanzen: Ein Programm auf dem Weg zur Sozialen Stadt? [Socially integrative city: Interim results: A programme on the way to the social city?] (pp. 165-178). Opladen: Leske + Budrich.

Gunder, M., \& Hillier, J. (2009). Planning in ten words or less: A Lacanian entanglement with spatial planning. Farnham: Ashgate.

Haraway, D. (1988). Situated knowledges: The science question in feminism and the privilege of partial perspective. Feminist Studies, 14(3), 575-599.

Jungk, S. (2001). Interkulturelle Öffnung sozialer Dienste und Ämter: eine Herausforderung für die Einwanderungsgesellschaft [Intercultural opening of social services and public administration: A challenge for the immigration society]. In E. Riehle (Ed.), Interkulturelle Kompetenz in der Verwaltung? Kommunikationsprobleme zwischen Migranten und Behörden [Interculture competence in public administration? Communication problems between immigrants and public authorities] (pp. 95-115). Wiesbaden: VS Verlag für Sozialwissenschaften.

Kuckartz, U., \& Rädiker, S. (2019). Analyzing qualitative data with MAXQDA: Text, audio, and video. Wiesbaden: Springer VS.

Landeshauptstadt Wiesbaden. (Eds.). (2015). Leitlinien Bürgerbeteiligung [Guidelines for citizen participation]. Wiesbaden: Landeshauptstadt Wiesbaden.

Renn, O. (2018). Real-world laboratories: The road to transdisciplinary research? Gaia. https://doi.org/ 10.14512/gaia.27.S1.1

Rose, G. (1997). Situating knowledges: Positionality, reflexivities and other tactics. Progress in Human Geography, 21(3), 305-320.

Roska, M. (2012). Umgang mit Vielfalt in der Kreisverwaltung: Vorschläge für die Implementierung interkultureller Kompetenz in der Verwaltung des Landkreises Gießen als Anstoß für eine interkulturelle Öffnung [Managing diversity in county government: Proposals for the implementation of interculture competence in the Gießen county administration as incentive for intercultural opening]. Frankfurt am Main: Deutsches Institut für Internationale Pädagogische Forschung.

Schnur, O., \& Drilling, M. (Eds.). (2009). Governance der Quartiersentwicklung: Theoretische und praktische Zugänge zu neuen Steuerungsformen [Governance of neighborhood development: Theoretical and practical approaches to new forms of governance]. Wiesbaden: Springer VS.

Scholl, C., \& Kemp, R. (2016). City labs as vehicles for innovation in urban planning processes. Urban Planning, 1(4), 89-102.

Scholten, P. (2020). Mainstreaming versus alienation: $A$ complexity approach to the governance of migration and diversity (global diversities). Basingstoke: Pal- grave Mc Millan.

Schröer, H. (2018). Vielfalt als kommunale Gestaltungsaufgabe: Interkulturelle Öffnung und Diversity Management als strategische Antworten [Diversity as municipal task: Intercultural opening and diversity management as strategic answers]. In F. Gesemann \& R. Roth (Eds.), Handbuch lokale Integrationspolitik in der Einwanderungsgesellschaft [Handbook local integration policy in the immigration society] (pp. 227-260). Wiesbaden: Springer VS.

Selle, K. (2019). Ende der Naivität? Öffentlichkeitsbeteiligung in der Stadtentwicklung: Anstiftungen zur Revision [The end of naivety? Public participation in urban development: Incitements for revision]. Berlin and Schwerte: vhw Bundesverband Wohnen + Stadtentwicklung e. $\mathrm{V}$.

SenStadtUm. (Eds.). (2011). Handbuch zur Partizipation [Participation manual]. Berlin: Kulturbuch-Verlag $\mathrm{GmbH}$.

SenSW. (Eds.). (2019). Gemeinsam Stadt machen! Leitlinien für Beteiligung von Bürgerinnen und Bürgern an Projekten und Prozessen der räumlichen Stadtentwicklung [Making city together! Guidelines for citizen participation in spatial urban development projects and processes]. Berlin: SenSW.

Stiftung Mitarbeit, \& ÖGUT. (Eds.). (2018). Bürgerbeteiligung in der Praxis [Citizen participation in practice]. Bonn: Verlag Stiftung Mitarbeit.

Strauss, A., \& Corbin, J. M. (1997). Grounded theory in practice. Thousand Oaks, CA: Sage.

Tasan-Kok, T., van Kempen, R., Raco, M., \& Bolt, G. (2013). Towards hyper-diversified European cities. Utrecht: Faculty of Geosciences of Utrecht University.

Terkessidis, M. (2004). Die Banalität des Rassismus: Migranten zweiter Generation entwickeln eine neue Perspektive [The banality of racism: Second generation immigrants develop a new perspective]. Bielefeld: transcript Verlag.

Terkessidis, M. (2017). Nach der Flucht. Neue Ideen für die Einwanderungsgesellschaft [After the flight. New ideas for the immigration society]. Stuttgart: Reclams Universalbibliothek.

Terkessidis, M. (2018). Interkultur [Interculture] (7th ed.). Berlin: Suhrkamp.

Valentine, G. (2002). People like us: Negotiating sameness and difference in the research process. In P. Moss (Ed.), Feminist geography in practice (pp. 116-126). Oxford: Blackwell.

Vertovec, S. (2007). Super-diversity and its implications. Ethnic and Racial Studies, 30, 1024-1054.

vhw. (2009). Migranten-Milieus: Ein Kompass für die Stadtgesellschaft [Migrant milieus: A compass for urban society]. Berlin: vhw Bundesverband Wohnen + Stadtentwicklung e. V.

vhw. (2018). Migranten, Meinungen, Milieus: vhwMigrantenmilieu-Survey 2018 [Migrants, opinions, milieus: vhw survey on migrant milieus 2018]. Berlin: vhw Bundesverband Wohnen + Stadtentwicklung e. V. 
Wanner, M., Hilger, A., Westerkowski, J., Rose, M., Stelzer, F., \& Schäpke, N. (2018). Towards a cyclical concept of real-world laboratories. disP: The Planning Review, 54(2), 94-114.
Young, I. M. (2005). Justice and the politics of difference. In S. Fainstein \& L. Servon (Eds.), Gender and planning (pp. 86-103). New Brunswick, NJ and London: Rutgers University Press.

\section{About the Authors}

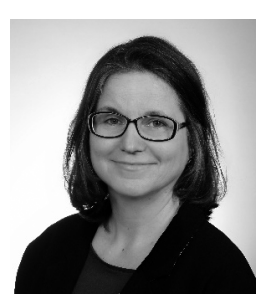

Sandra Huning is a Senior Lecturer and Researcher at TU Dortmund University, Faculty of Spatial Planning, in the Urban and Regional Sociology department. She holds a PhD from Technische Universität Berlin. Her research areas include planning theories, space, gender and feminism, and sustainability in urban research and policies. She is also interested in methodological questions of empirical (transdisciplinary) urban studies and planning research.

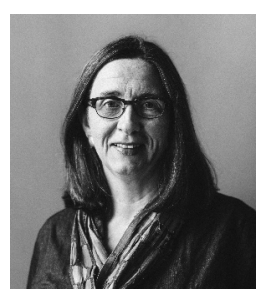

Christiane Droste is a Managing Director and Senior Researcher at UP19 Stadtforschung + Beratung $\mathrm{GmbH}$, a Berlin private agency for urban research and consultancy. Her research focuses on urban development and governance, social and community-oriented housing, with a particular interest in gender diversity in these fields as well as in architecture and planning. She holds a PhD in Philosophy from Westminster University London. Also, she coordinates the Berlin agency against housing discrimination.

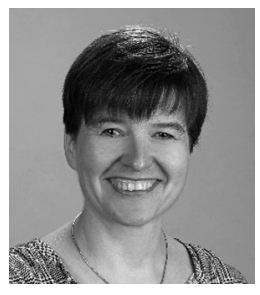

Katrin Gliemann is a Senior Lecturer and Researcher at TU Dortmund University, Faculty of Spatial Planning, Department of International Planning Studies. Her research and teaching activities focus on socio-spatial phenomena in national and international contexts, especially the nexus of migration and urban development. She also has particular expertise in qualitative research methods and is very interested in new forms of knowledge generation such as the RWL approach. Katrin Gliemann holds a PhD in Spatial Planning from TU Dortmund University. 